TRANS · núm. $24 \cdot 2020$

MISCELÁNEA $\cdot 283-302$

La ciencia se publica en inglés y su divulgación se hace indispensable en las sociedades modernas. En esta investigación se analiza la traducción-divulgación de títulos científicos altamente especializados en las ediciones digitales de los periódicos ABC, El Mundo, El País, La Presse (Canadá), Le Figaro y Le Monde. Utilizando una metodología descriptiva, se analiza cómo se traducen estos títulos de lo altamente especializado en inglés a lo divulgativo en español y francés y se contrasta su traducción en los seis periódicos arriba señalados. Los resultados muestran que existe una tendencia homogeneizadora en los titulares, conllevando así a traducciones «glocales».

PALABRAS CLAVE: Traducción de títulos científicos, traducción periodística, divulgación científica, estrategias de traducción, inglés/ español/francés, prensa digital.

\title{
Traducción y divulgación de los títulos científicos altamente especializados en la prensa española y francófona
}

\author{
Hend GhidhaOUI \\ Universidad de Salamanca
}

\section{The Translation and Popularization of Highly Specialized Scientific Titles in the Spanish and French-Speaking Press}

English is the lingua franca of science and its popularization is indispensable for modern societies. This paper analyzes the translation-popularization of highly specialized scientific titles -from English into Spanish and French- as newspaper headlines in the digital edition of ABC, El Mundo, EL País, La Presse (Canada), Le Figaro and Le Monde. Using a descriptive methodology, we study how these titles are translated from highly specialized English into popularized Spanish and French and we contrast their translation in the six newspapers mentioned above. The results of this study demonstrate some homogeneity in the headlines leading to 'glocal' translation.

KEY WORDS: Translation of scientific titles, news translation, popularization of science, translation strategies, English/Spanish/French, digital media. 


\section{1. INTRODUCCIÓN}

Vivimos en un mundo globalizado en el que el inglés se ha convertido en la nueva lengua del poder económico y político (Guyot, 2010: 52). Las revistas más prestigiosas se publican y se editan en Estados Unidos o en el Reino Unido en inglés: «La science et la technique parlent désormais anglais et sa maîtrise est dès lors indispensable pour parler science et technique» (Durand, 2010: 64). Según unos datos cuantitativos recogidos por Ammon (2013: 115) sobre el uso proporcional de las lenguas en las publicaciones científicas entre 1880 y 2005, se aprecia el ascenso del inglés a partir de mediados del siglo XX frente al declive de los demás idiomas. Todo apunta a que el inglés se ha impuesto como idioma internacional, sobre todo en los ámbitos especializados y se ha transformado en lingua franca de la ciencia.

La divulgación de los avances de la ciencia se ha tornado necesaria. Por un lado, informa a la sociedad de los últimos avances científicos; por otro, permite a los científicos legitimar sus descubrimientos y obtener más financiación (Jacobi, 1999: 29-31). Así pues, con el inglés como idioma vehicular de la ciencia y la necesidad de vulgarización científica, se precisa una doble labor de mediación. Hace falta una traducción interlingüística cuando se traduce el texto científico altamente especializado del inglés a otro idioma, así como una traducción intralingüística en la que se «traduce» el lenguaje científico en lenguaje común comprensible para los legos. Esta doble mediación se hace a través de la traducción periodística cuando se divulga el saber en la prensa. Sin embargo, a pesar de la ubicuidad de la traducción a lo largo de este proceso, esta es invisible al tratarse de una tarea llevada a cabo por el periodista-traductor que la considera como parte del trabajo periodístico (García
Suárez, 2005; Bielsa, 2016; entre otros). Además, las informaciones «sont contextualisées, issues d'une source précise, vérifiées, corrigées, modifiées, adaptées à la fois à leur lectorat et à leur support. Elles sont transéditées, ou transadaptées, c'est-à-dire éditées et traduites de manière selective [...]» (Gambier, 2010: 18). Para que la traducción funcione en la cultura meta, hay que adaptarla a las convenciones textuales de esta última, ofreciendo versiones locales de las que no se sospecha que son fruto de la traducción (Hernández Guerrero, 2009: 63).

Los artículos científicos ya no van dirigidos a los pares sino a un lector lego con lengua y cultura diferentes. Por tanto, el periodista-traductor además de traducir los textos científicos altamente especializados del inglés a los demás idiomas, los reformula usando un lenguaje accesible para los no iniciados (Jacobi, 1999: 82) y los recontextualiza en una nueva situación comunicativa (Calsamiglia, 1997). Los adapta, asimismo, al nuevo contexto sociolingǘstico y cultural, ajustándolos a las convenciones textuales del nuevo medio en el que se van a publicar (Hernández Guerrero, 2004: 278). Estamos ante un nuevo discurso construido desde otro punto de vista (Calsamiglia 1997): «El divulgador no es una cuerda de transmisión neutra sino que es un creador del sentido nuevo que puede tomar el conocimiento cuando se contextualiza en la vida social». El vulgarizador contextualiza el saber y crea un sentido nuevo, es decir, una representación nueva. Como creador, reescribe el texto científico adaptándolo a un nuevo público. Así pues, todas esas pautas son necesarias para traducir la ciencia y divulgarla, a sabiendas de que no hay divulgación ni reescritura sin ideología y sin manipulación (Roqueplo, 1983; Bassnett y Lefevere, 1993).

Partiendo de la dominación del inglés y la necesidad de difundir los avances científicos, nos 
centraremos en la divulgación científica en la prensa. Esta se difunde a través de la traducción periodística. Este estudio preliminar se ciñe únicamente a los títulos ${ }^{1}$. Partimos del hecho de que los títulos se adaptan a una nueva situación comunicativa y a las convenciones textuales de titulación vigentes en la lengua meta. Nuestra hipótesis es que un mismo título traducido en medios de lengua, cultura e ideología diferentes se traducirá de diferente manera al tener que localizarse $^{2}$ en una nueva situación comunicativa.

\subsection{Objetivos del estudio}

En este artículo nos centraremos en un elemento representativo de los artículos, los títulos, dado que

[...] constituyen la unidad de traducción ideal: son elementos funcionales compactos, ni muy largos, ni tampoco muy cortos, no muy complejos, pero tampoco muy sencillos [...]. Tanto en la cultura de partida como en la cultura meta, el título funciona solamente como entidad completa [...] (Nord, 1998: 70).

Desde el punto de vista traductológico, el estudio de los títulos es interesante porque reúnen el sentido global del artículo. Utilizamos títulos de artículos científicos altamente especializados que se traducen en la prensa como noticias científicas cuyo objetivo principal es comunicar hechos científicos a un público profano.

I Es preciso señalar que «un titular puede componerse de cintillo, antetítulo, título, subtítulo y sumario (uno o más), o solamente de uno o dos de estos elementos (entre los que figurará siempre el título)» (Libro de estilo de El País, 2014: 81), por lo que usaremos titular y título como sinónimos.

2 Seguimos a Orengo (2005) quien aplica la noción de localización a la traducción periodística, dado que se transforma el texto y se adapta a la nueva situación comunicativa, dando lugar a noticias locales.
Nos planteamos como objetivos ver cómo se traducen los títulos científicos altamente especializados en la prensa y contrastar su traducción en contextos lingüísticos y culturales diferentes, tomando como muestra tres periódicos españoles y tres francófonos ${ }^{3}$. Utilizando una metodología descriptiva (Toury, 2004), analizamos la traducción-divulgación de estos títulos en las ediciones digitales de los periódicos $A B C$, El Mundo, El País, La Presse, Le Figaro y Le Monde.

Con este trabajo se intenta paliar la ausencia, en España, de investigaciones centradas en la traducción-divulgación de títulos científicos altamente especializados en la prensa. Por tanto, se intenta contribuir tanto a los Estudios de Traducción como a los de las Ciencias de la Información. Consideramos que una investigación acerca de este tipo de traducción en contextos diferentes es muy importante para arrojar luz sobre cómo se traducen estos títulos y los factores que habrá que tener en cuenta a la hora de enfrentarse a una traducción de estas características.

Este artículo se organiza como sigue: primero, haremos un breve repaso a la bibliografía relacionada con la traducción de títulos; después, explicaremos los criterios de selección del corpus y describiremos el análisis realizado, así como los resultados obtenidos. Por último, interpretaremos los resultados y presentaremos las conclusiones extraídas del análisis.

\subsection{Estrategias de traducción-divulgación:}

Para divulgar y traducir un título científico en la prensa es necesario recontextualizarlo en una nueva situación comunicativa, es decir, introducir los cambios necesarios para adaptarlo al lec-

3 Con el uso de francófono no pretendemos referirnos a todos los países francófonos, sino a los dos periódicos franceses y el canadiense de expresión francesa objeto de este estudio. 
286 tor, el medio, la cultura, etc. Como bien señala Ciapuscio (1997), el paso del artículo científico a la noticia puede considerarse como una simplificación general que permite hacer accesibles los contenidos científicos a los no expertos. Menciona, asimismo, que la reformulación del nuevo texto se hace mediante el uso de tres estrategias: expansión, reducción y variación. La expansión permite incluir en el texto contenido nuevo. La reducción puede presentarse bajo dos formas: eliminar información por su irrelevancia en la nueva situación comunicativa o condensar el contenido. La variación son los cambios que se realizan en el texto reformulado.

En traducción periodística no solo hay que traducir el texto origen, sino también adaptarlo a las convenciones textuales de la lengua meta y ajustarlo a las normas del nuevo medio. Según Hernández Guerrero (2006: 132), en traducción periodística se tiende al uso de ciertas técnicas específicas que permiten modificar el texto de llegada. Estas son la amplificación, la compresión y la elisión. La amplificación consiste en introducir aclaraciones inexistentes en el texto origen. La compresión consiste en sintetizar los elementos del texto de partida. La elisión ocurre cuando se omite parte del texto original. Se puede observar que las dos primeras técnicas de divulgación y de traducción coinciden. En divulgación se combinan las dos técnicas de compresión y elisión. La diferencia radica en la técnica de variación, inexistente entre las señaladas por Hernández Guerrero.

\subsection{Traducción de los títulos}

Para entender cómo se traducen los títulos científicos altamente especializados es preciso entender cómo funcionan, por un lado, los títulos en general y, por otro, tanto los científicos altamente especializados como los periodísticos.
Martin-Lagardette (2000: 126) compara el título con la cara de una persona que vemos por primera vez:

Quand vous rencontrez quelqu'un pour la première fois, vous vous faites immédiatement une impression globale à travers son regard, son visage. Vous savez tout de suite si la personne est triste ou gaie, si elle vous plaît ou non. Le titre d'un article, c'est aussi son visage. Un coup d'œil suffit pour avoir une idée de l'ensemble.

El título lo resume todo, permite calibrar la calidad de su contenido y nos ayuda a decidir continuar la lectura o abandonarla.

Los estudios realizados sobre los títulos científicos altamente especializados son numerosos (Goodman et al., 2001; Baicchi, 2003; Soler, 2007, 2011; entre otros). Soler (2011: 124) señala que:

Titles are succinct descriptive labels of texts and are meant to fulfil different purposes [...]. In science, in particular, they are ideally relevant to present the content of a study and, in general, they are self-explanatory to their readers. They thus result from a set of requisites, among which being informative and precise, concise, easily classifiable and storable in databases, [...].

Así, el título de un trabajo científico tiene que representarlo y promocionarlo siendo conciso y preciso. En cambio, los estudios sobre su traducción son escasos. El único trabajo del que tenemos constancia es el de Soler (2015) que trata de la traducción del inglés al español y viceversa de títulos científicos altamente especializados en América del Sur en un contexto similar, es decir, en una traducción dirigida a los pares. La autora reflexiona sobre si hace falta traducirlos o no y sobre el cumplimiento de los criterios de precisión y corrección en la lengua de llegada. Concluye que los títulos científicos altamente especializados: 
1) si forman parte de un curriculum vitae en el sector geográfico determinado para este trabajo, no se traducen excepto en los casos en que el encargo de traducción requiera una traducción pública. 2) Si el traductor no es científico, deberá leer el artículo en su totalidad particularmente en el caso de los títulos metafóricos y confirmar con el científico que el título sea también efectivo metafóricamente en la lengua de llegada. 3) Si quien hace la traducción es científico pero no es traductor, debe corroborar que se cumpla el principio de corrección [...] (Soler, 2015: 24).

En el estudio que nos ocupa, nos centramos en la traducción de los títulos científicos altamente especializados en la prensa. Ya no estamos en una situación comunicativa horizontal en la que el título origen (TO) y el título meta (TM) van dirigidos a los pares, sino que estamos en una situación vertical en la que el TO es altamente especializado publicado en una revista dirigida a los pares, en inglés; y la traducción se publica en la prensa y va dirigida a un lector lego, en países diferentes con contextos lingüísticos y socioculturales distintos. El resultado de la traducción de un título científico altamente especializado en la prensa es un titular de prensa, así que es conveniente pasar revista a las características de los titulares de prensa y su traducción.

Según Gómez Mompart (1982: 53-68), los títulos dependen de varios factores: el momento, el medio, la orientación del medio, la lengua empleada, la tradición periodística y cultural, el género periodístico, la sección, la página, el lugar y la mancha en la misma, el cuerpo y el tipo de letras. Así pues, el título cambia según la lengua y las convenciones de redacción y de titulación específicas de cada periódico (Aştirbei, 2011: 36). Los titulares «aparentemente actúan como resúmenes del texto de la noticia» (Van Dijk, 1990: 61). Son el agarre, dan una visión global de la noticia e incitan a su lectura (García-Cerviñón, 2017: 107).
En traducción periodística, al contrario que en la traducción de títulos científicos altamente especializados, la literatura sobre la traducción de titulares es copiosa (Reque de Coulon, 2002; Hernández Guerrero, 2004; Andújar Moreno, 2006; Aştirbei, 2011; Vella Ramírez y Martínez López, 2012; Al Duweiri y Baya Essayahi, 2016; Luna Alonso, 2019; entre otros). Hernández Guerrero (2004) estudia la traducción de los titulares del francés al español y pone de manifiesto que los textos periodísticos no son uniformes. Cada género periodístico posee sus propias características y «titula sus variedades textuales de una manera particular» (Hernández Guerrero, 2004: 273), lo que condiciona los títulos de los artículos y hace que sus características cambien según el género periodístico, por tanto también su traducción. Usando un corpus de artículos periodísticos franceses de Le Monde y Libération y su traducción en El País y El Mundo, la autora señala que:

- gran parte de los títulos de los artículos de opinión se traducen literalmente: «Influye en esta fidelidad el respeto a la voluntad del autor del original, pero también el hecho de que en francés las normas de titulación de estos textos son muy similares a las de nuestra lengua» (ibid.: 279-280);

- los títulos de los artículos informativos no se traducen literalmente.

En las conclusiones de su estudio la autora apunta a que la mayoría de los titulares periodísticos no se traducen literalmente.

Andújar Moreno (2006) y Aştirbei (2011), analizando un corpus de títulos de artículos periodísticos publicados en Le Monde diplomatique en francés y su versión española y rumana respectivamente, observan que la cultura origen tiene mucho peso en orientar las traducciones y muestran que las traducciones literales son las más frecuentes. 
288

Estas discrepancias en los resultados en cuanto a las traducciones más frecuentes se deben a la diferencia en los corpus utilizados (diferentes periódicos versus mismo medio con ediciones en otros idiomas). En la bibliografía consultada se afirma que cada género periodístico titula sus artículos de una forma determinada y las decisiones traslativas dependen de ello y de la nueva situación comunicativa.

\section{MÉTODO}

\subsection{Corpus}

Hemos reunido un corpus de títulos de artículos científicos publicados en revistas científicas altamente especializadas en inglés y sus traducciones aparecidas como noticias científicas publicadas en las ediciones digitales de $A B C, E l$ Mundo, El País, Le Figaro, Le Monde y La Presse. Son artículos en los que se publican avances y descubrimientos científicos sobre el ébola publicados durante el peor brote de esta enfermedad (2014-2016).

Acotamos nuestro corpus a los títulos que cumplen con los siguientes criterios:

- artículo fuente publicado en una revista especializada en inglés;

- divulgado como noticia científica en la prensa tanto en español como en francés.

El total de títulos recopilados sobre el ébola fue de 2199. No obstante, aplicando los criterios de selección nuestro corpus se fijó en un total de 26 títulos, es decir, el 1,8\%:

- cuatro títulos de artículos científicos en inglés publicados en las revistas especializadas Nature, Nature Medicine, Science Translational Medicine y The New England Journal of Medicine;
- once títulos de noticias científicas en español aparecidos en $A B C$, El Mundo y El País;

- once títulos de noticias científicas en francés aparecidos en La Presse, Le Figaro y Le Monde.

Basándonos en este corpus, estudiamos cómo se divulgan y traducen los títulos científicos altamente especializados dados a conocer en inglés en los periódicos antes señalados y en idiomas diferentes.

Para analizar el corpus seleccionado, extraeremos la información contenida en los títulos científicos, luego observaremos si se mantiene en las traducciones y cómo. Para ello, nos fijaremos en las técnicas de divulgación y traducción usadas para la traducción de los títulos científicos altamente especializados en la prensa y contrastaremos las decisiones tomadas en los dos idiomas objeto de estudio.

\subsection{Análisis}

Utilizando una metodología descriptiva (Toury, 2004), nos proponemos comprobar si la traducción de los títulos científicos altamente especializados en la prensa se rige más bien por la traducción literal para mantener la precisión y concisión del lenguaje científico o no. También pretendemos ver si las decisiones de traduccióndivulgación son homogéneas y comunes entre los distintos medios o cambian según la lengua, cultura, ideología, etc.

Un concepto muy útil para entender la traducción de títulos científicos en prensa es el de la política de traducción definida esta como «los factores que regulan la elección de tipo textual» (Toury, 2004:100). A las redacciones llega un flujo de información constante que cada redacción adapta a sus necesidades. Tiene que seleccionar la información que será noticia y descartar otras 
(cf. la figura de gatekeeping en Valdeón, 2016). La elección de los textos traducidos y divulgados no se hace de manera aleatoria. La selección de los artículos en las redacciones se hace teniendo en cuenta la importancia de traducir y divulgar los últimos descubrimientos científicos para que la sociedad y los lectores estén informados de los avances de la pandemia y de los últimos descubrimientos que se han hecho en el ámbito científico. También, de entre sus fuentes de información, utilizan las revistas científicas, sobre todo, las que tienen gabinetes de prensa que «redactan en lenguaje periodístico los contenidos principales de lo que publican» (Elías, 2008: 87), lo que hace que se divulgan más los contenidos de estas revistas porque elaboran noticias «precocinadas» (ibid.: 88).

Durante el brote de ébola (2014-2016) el primer caso apareció en Guinea en diciembre de 2013, no obstante, los medios intensificaron la cobertura de este hecho tras el contagio de dos cooperantes estadounidenses en agosto de 2014. La cobertura mediática del ébola aumentó con la llegada de casos importados a EE.UU. y Europa ${ }^{4}$. Por tanto, se importan textos procedentes de las revistas que tienen gabinetes de prensa, porque proporcionan a los periodistas científicos textos listos a divulgar.

Los siguientes ejemplos nos permiten ver cómo se traducen y divulgan los títulos científicos altamente especializados en los periódicos objeto de estudio.

I. EN - Marburg virus infection in nonhuman primates: Therapeutic treatment by lipidencapsulated siRNA

Science Translational Medicine, Thy, et al., 20/08/2014, ANEXO 1

\footnotetext{
4 El sacerdote Miguel Pajares se contagió en Liberia y murió después de su repatriación a España.
}

a. ES - Diseñan una posible cura para el «hermano» del ébola, el virus Marburgo $A B C$, Gonzalo López Sánchez, 20/08/2014, ANEXO 2

b. ES - Una esperanza para el 'primo' más cercano del ébola

El Mundo, Cristina G. Lucio, 21/08/2014, ANEXO 2

c. FR - Un traitement pour le virus Marburg, cousin d'Ebola

Le Figaro, Jonathan Herchkovitch, 21/08/2014, ANEXO 3

d.FR - Vers un traitement contre le virus de Marburg, très proche de celui d'Ebola Le Monde, Le Monde y AFP, 21/08/2014, ANEXO 3

En este ejemplo vemos cómo los títulos divulgativos omiten los tecnicismos existentes en el título científico en inglés y se centran en el hallazgo propiamente dicho: el descubrimiento de un remedio contra el virus Marburgo.

Para visualizar el mantenimiento $\mathrm{u}$ omisión de la información existente en el título científico altamente especializado, extraemos la información contenida en el título en inglés y buscamos equivalentes de divulgación-traducción en los titulares de prensa.

Recogemos los resultados del ejemplo 1 en el cuadro 1. Observamos que los títulos periodísticos no mantienen la misma información. La información especializada de los títulos científicos se adapta y se reformula de distintas maneras. La información va dirigida a diferentes lectores (especialista, semilego o lego) de habla distinta y se recontextualiza en una nueva situación comunicativa. A nivel divulgativo y traductológico, vemos que de los cuatro elementos informativos existentes en el título científico en inglés solo se mantienen dos. Para la divulgación-traducción de «nonhuman primates»y «lipid-encapsula- 
Cuadro 1. Reformulación de la información del ejemplo 1 en su paso de lo especializado a lo divulgativo

\begin{tabular}{|c|c|c|c|c|c|}
\hline EN & $\begin{array}{c}\text { Science } \\
\text { Translational } \\
\text { Medicine }\end{array}$ & Marburg virus infection & $\begin{array}{c}\text { nonhuman } \\
\text { primates }\end{array}$ & $\begin{array}{l}\text { therapeutic } \\
\text { treatment }\end{array}$ & $\begin{array}{c}\text { lipid-encapsulated } \\
\text { siRNA }\end{array}$ \\
\hline \multirow[t]{2}{*}{ ES } & $A B C$ & $\begin{array}{l}\text { el "hermano" del ébola, } \\
\text { el virus Marburgo }\end{array}$ & - & una posible cura & - \\
\hline & El Mundo & $\begin{array}{c}\text { el 'primo' más cercano } \\
\text { del ébola }\end{array}$ & - & una esperanza & - \\
\hline \multirow[t]{2}{*}{ FR } & Le Figaro & $\begin{array}{c}\text { le virus Marburg, cousin } \\
\text { d'Ebola }\end{array}$ & - & un traitement & - \\
\hline & Le Monde & $\begin{array}{l}\text { le virus de Marburg, très } \\
\text { proche de celui d'Ebola }\end{array}$ & - & un traitement & - \\
\hline
\end{tabular}

ted siRNA» se ha optado por la reducción-elisión tanto en los periódicos de expresión española como francesa. El nuevo lector no es experto y lo más relevante para él es el descubrimiento.

En el caso de «Marburg virus infection» se ha omitido «infection» (reducción-compresión) y se ha introducido información nueva (expansión-amplificación). En las traducciones el virus de Marburgo es el elemento que se reformula, definiéndose como cercano al virus del ébola. Los títulos nos proporcionan diferentes posibilidades: en los españoles encontramos virus «gemelo», «hermano» $\mathrm{y}$ «primo»; y en los franceses «cousin», «très proche de». Todas estas opciones dejan entender que se trata de un virus que pertenece a la familia del ébola, enfermedad conocida y temida. Por consiguiente, si el remedio es eficaz contra uno, podría serlo contra el otro; de ahí la importancia de relacionar ambos virus en los títulos, dado que los artículos se publicaron en pleno brote del ébola.

En el caso de «Therapeutic treatment», los títulos de $A B C$ y El Mundo optan por una variación donde se habla respectivamente de «una posible cura»y «una esperanza», lo que muestra una cierta cautela con respecto al descubrimiento. Podemos decir que los títulos españoles son más escépticos. En cambio, los títulos franceses de $L e$ Figaro y Le Monde utilizan formas más directas y optimistas. De hecho, hablan de «un traitement», dando por hecho su eficacia. Estamos ante una reducción-compresión

En el ejemplo 1 vemos que el título científico altamente especializado no se traduce literalmente. Se omiten los tecnicismos y solo se mantiene parte de la información existente en el título científico altamente especializado: un tratamiento contra el virus de Marburgo. A partir de dicha información se usan varias técnicas divulgativas para elaborar títulos dirigidos a un nuevo lector -no especialista-. Observamos que las soluciones propuestas por los periódicos no presentan diferencias ni a nivel divulgativo ni a nivel traductológico. Los títulos españoles como los franceses coinciden tanto en la información mantenida como en la omitida. Se selecciona la misma información y se reformula el mismo elemento relacionándolo en todos los casos con el virus del ébola. Además, la estructuración de la información es similar y los ini- 
Cuadro 2. Reformulación de la información del ejemplo 2 en su paso de lo especializado a lo divulgativo

\begin{tabular}{|c|c|c|c|c|c|}
\hline EN & Nature & reversion & $\begin{array}{l}\text { advanced ebola } \\
\text { virus disease }\end{array}$ & nonhuman primates & Zmapp \\
\hline \multirow[t]{3}{*}{ ES } & $A B C$ & $\begin{array}{l}\text { demuestra su } \\
\text { efectividad }\end{array}$ & el ébola & primates & $\begin{array}{l}\text { el fármaco contra el } \\
\text { ébola Zmapp }\end{array}$ \\
\hline & El Mundo & un espaldarazo & - & - & Zmapp \\
\hline & El País & cura & el ébola & monos & el fármaco experimental \\
\hline \multirow{3}{*}{ FR } & La Presse & lueur d'espoir & virus Ebola & - & - \\
\hline & Le Figaro & l'espoir & - & - & $\begin{array}{l}\text { des premiers traite- } \\
\text { ments expérimentaux }\end{array}$ \\
\hline & Le Monde & l'espoir & ebola & - & $\begin{array}{l}\text { un traitement contre } \\
\text { Ebola }\end{array}$ \\
\hline
\end{tabular}

cios de los títulos son parecidos, sobre todo, en los títulos franceses.

2. EN - Reversion of advanced Ebola virus disease in nonhuman primates with Zmapp Nature, Qui et al., 29/08/2014, ANEXO 1 a. ES - El fármaco contra el ébola ZMapp demuestra su efectividad en primates $A B C$, efe, 29/08/2014, ANEXO 2 b. ES - Un espaldarazo para ZMapp

El Mundo, Cristina G. Lucio, 29/08/2014, ANEXO 2

c. ES - El fármaco experimental cura el ébola en monos

El País, Nuño Domínguez, 29/08/2014, ANEXO 2

d.FR - Virus Ebola: Lueur d'espoir canadienne au bout d'un tunnel qui s'obscurcit

La Presse, Laura-Julie Perreault, 30/08/2014, ANEXO 3

e. FR - L'espoir des premiers traitements expérimentaux

Le Figaro, Cyrille Vanlerberghe, 29/08/2014, ANEXO 3 f. FR - L'espoir d'un traitement contre Ebola conforté par de nouvelles études

Le Monde, Sandrine Cabut, 30/08/2014, ANEXO 3

En el cuadro 2 observamos que no se mantienen los mismos elementos en todos los títulos periodísticos. En $A B C$ y El País se conservan los cuatro elementos informativos, en Le Monde tres y en El Mundo, La Presse y Le Figaro solo se recogen dos elementos.

Para «reversion», en los títulos españoles encontramos varias posibilidades en las que se intenta plasmar el resultado del tratamiento. En los títulos en francés se recurre al uso de «l'espoir» en los tres títulos, dado que la reversión de los efectos del virus es una esperanza para su curación. En todos los títulos se usa la variación para transmitir este elemento. En el caso de «advanced Ebola virus disease» encontramos «el ébola» en $A B C$ y El País, «Ebola» en Le Monde y «virus Ebola» en La Presse. En estos casos prima la técnica de reducción-compresión, ya que se usa el sustantivo común, mientras que en El Mundo y Le Figaro se utiliza la reducción-elisión, dado que 
292 no se alude a la enfermedad. «Nonhuman primates» aparece reducida en los títulos de $A B C$ y $E l$ País, usando el primero un término más técnico «primates» y el segundo más general «monos»; en los demás se elimina (reducción-elisión). Vemos que en el título de Nature aparece directamente «Zmapp» sin ningún tipo de explicación dado que los pares no la necesitan, mientras que en $A B C$ aparece definido como «el fármaco contra el ébola». Es una expansión-amplificación. En Le Figaro y Le Monde se usa una variación, se reformula «Zmapp» por «des premiers traitements expérimentaux» $\mathrm{y}$ «un traitement contre Ebola» respectivamente. El título de El Mundo introduce «ZMapp» sin reformularlo.

En el caso de este ejemplo observamos que «reversion» $\mathrm{y}$ «Zmapp» son los elementos informativos que se reproducen en prácticamente todos los titulares. Cada título los reformula de manera determinada usando, en el caso de «reversion» la misma técnica divulgativa. Podemos ver cómo los títulos de $A B C$ y El País son los que reproducen más elementos procedentes del título original (el fármaco ZMapp, contra el ébola, efectividad, en primates). A pesar de ser dos periódicos con líneas editoriales opuestas, presentan mucha similitud en cuanto a la información seleccionada, por un lado, y la elaboración de los títulos, por otro. En el título de El Mundo se hace hincapié en el fármaco, mientras que los títulos en francés se centran en la esperanza que genera el tratamiento. Cabe señalar la coincidencia de los títulos francófonos en el uso del vocablo «espoir» con el que comienzan, así como la similitud entre los dos títulos de Le Figaro y Le Monde.

En el ejemplo 2, al igual que en el primero, tampoco se opta por una traducción literal del título científico. Se observan decisiones diferentes: $A B C$ y El País se muestran más fieles a la información recogida en el título científico y más informativos, El Mundo se decanta por un título muy bre- ve y expresivo a la vez que poco informativo. Los títulos francófonos, en cambio, presentan mucha similitud entre ellos, ya que sus comienzos son parecidos. Este caso muestra traducciones meta semejantes dentro de un mismo idioma, así como coincidencia en el elemento que se explica (ZMapp) con decisiones divulgativas afines, excepto en El Mundo y La Presse títulos en los que se omite este elemento.

3. EN-Chimpanzee adenovirus vaccine generates acute and durable protective immunity against ebolavirus challenge

Nature Medicine, Stanley et al., 07/09/2014, ANEXO 1

a. ES - Una vacuna contra el ébola logra inmunizar a primates durante 10 meses

$A B C, 1$, efe, 08/09/2014, ANEXO 2

b. ES - Una vacuna experimental contra el ébola protege a monos durante diez meses $A B C$, 2, Agencias, 09/09/2014, ANEXO 2

c. ES - La primera vacuna frente al ébola muestra su protección en animales

El Mundo, Ángeles López, 07/09/2014, ANEXO 2

d. FR - Ebola: un vaccin expérimental validé par les essais sur des singes

La Presse, AFP, 07/09/2014, ANEXO 3

e. FR - Ebola: un vaccin validé chez les singes

Le Figaro, Le Figaro y AFP,07/09/2014, ANEXO 3

f. FR - Ebola: un vaccin expérimental validé par les essais sur des singes

Le Monde, Le Monde y AFP, 07/09/2014, ANEXO 3

El cuadro 3 recoge la información mantenida en la divulgación y traducción de los diferentes títulos. Para «chimpanzee» vemos que en todos los títulos se usa la variación. Encontramos un uso más especializado en $A B C$ (1) «primates» y 
Cuadro 3. Reformulación de la información del ejemplo 3 en su paso de lo especializado a lo divulgativo

\begin{tabular}{|c|c|c|c|c|c|c|}
\hline EN & $\begin{array}{c}\text { Nature } \\
\text { Medicine }\end{array}$ & chimpanzee & adenovirus vaccine & $\begin{array}{l}\text { generates } \\
\text { protective } \\
\text { immunity }\end{array}$ & $\begin{array}{c}\text { acute and } \\
\text { durable }\end{array}$ & $\begin{array}{c}\text { against } \\
\text { ebolavirus } \\
\text { challenge }\end{array}$ \\
\hline \multirow[t]{3}{*}{ ES } & $A B C, 1$ & primates & una vacuna & logra inmunizar a & $\begin{array}{l}\text { durante } 10 \\
\text { meses }\end{array}$ & contra el ébola \\
\hline & $A B C, 2$ & monos & $\begin{array}{l}\text { una vacuna } \\
\text { experimental }\end{array}$ & protege a & $\begin{array}{c}\text { durante diez } \\
\text { meses }\end{array}$ & contra el ébola \\
\hline & El Mundo & animales & la primera vacuna & $\begin{array}{l}\text { muestra su pro- } \\
\text { tección en }\end{array}$ & - & frente al ébola \\
\hline \multirow[t]{3}{*}{ FR } & La Presse & singes & $\begin{array}{c}\text { un vaccin } \\
\text { expérimental }\end{array}$ & $\begin{array}{c}\text { validé par les } \\
\text { essais }\end{array}$ & - & Ebola \\
\hline & Le Figaro & singes & un vaccin & validé & - & Ebola \\
\hline & Le Monde & singes & $\begin{array}{c}\text { un vaccin } \\
\text { expérimental }\end{array}$ & $\begin{array}{c}\text { validé par les } \\
\text { essais }\end{array}$ & - & Ebola \\
\hline
\end{tabular}

usos más generales en el resto de los titulares: «monos» en $A B C(2)$, «animales» en El Mundo y «singes» en La Presse, Le Figaro y Le Monde. Para «adenovirus vaccine», los dos idiomas se decantan por un uso más general, sin detallar el tipo de la vacuna. En $A B C$ (1) se utiliza «una vacuna» y en Le Figaro «un vaccin»; en $A B C$ (2), Le Monde y La Presse «una vacuna experimental» y «un vaccin expérimental»; en El Mundo «la primera vacuna». Se puede apreciar una decisión divulgativa de reducción en $A B C$ (1) y Le Figaro y de variación en los demás títulos. Para «generates protective immunity» existen varias reformulaciones. Los dos artículos de $A B C$, a pesar de dirigirse al mismo público y publicarse en la sección Sociedad, optan respectivamente por el uso de «logra inmunizar»y «protege». En El Mundo encontramos «muestra su protección». En la prensa francesa, este elemento se transmite mediante «validé» en Le Figaro y «validé par les essais» en Le Monde y La Presse. En los tres casos se utiliza la variación para transmitir la eficacia probada de una vacuna, dado que cura o protege contra el virus. Para «acute and durable», en $A B C$ se recoge la duración mediante «durante 10 meses» o «durante diez meses». En El Mundo, La Presse, Le Figaro y Le Monde no se traduce, es una reducción-elisión. En «against ebolavirus challenge» se usan las técnicas de reduccióncompresión, utilizando «el ébola» en lugar de «virus del ébola»y eliminando «challenge». En los diarios francófonos se usa también la reducción-compresión, apareciendo «Ebola» como una etiqueta al principio, seguida de dos puntos. Estos sirven para introducir el elemento clave (Chartier, 2000: 36).

El análisis del ejemplo 3 muestra que la información existente en el título científico (chimpan- 
294 cé, vacuna, protección, duradera, contra el ébola) se recopila en los títulos de $A B C$ y en el resto de los títulos solo se reproducen cuatro elementos. También se observa que en los títulos españoles se intenta una mayor fidelidad en la reformulación de los elementos, los títulos franceses, en cambio, muestran más libertad (logra inmunizar versus validé). Se ve, asimismo, que el título de $L e$ Figaro es una forma acortada de los títulos de $L a$ Presse y Le Monde, los títulos de estos últimos son idénticos. Este ejemplo muestra cómo periódicos de países diferentes (Francia y Canadá), independientemente de sus líneas editoriales, proporcionan títulos idénticos procedentes de agencias.

En las traducciones españolas existen coincidencias con las decisiones tomadas en el ejemplo 1 , los tres títulos reproducen prácticamente la misma información, realizando cambios a nivel de las palabras utilizadas. Los títulos en francés, por su parte, son parcialmente idénticos - coincidiendo así con lo observado en el ejemplo 2-y se decantan por decisiones diferentes de las españolas.
4. EN - Ebola Virus Disease in West Africa - The first 9 Months of the Epidemic and Forward Projections

The New England Journal of Medicine, Aylward et al., 23/09/2014, ANEXO 1

a. ES - En el peor escenario, EE.UU. prevé 1,4 millones de infectados en enero

$A B C$, Eduardo S. Molano, 24/09/2014, ANEXO 2

b.ES - EE.UU. teme 1,4 millones de casos de ébola antes de enero de 2015

El Mundo, efe y Reuters, 23/09/2014, ANEXO 2

c. ES - La OMS teme que el brote de ébola supere los 20.000 casos en noviembre

El País, Agencias, 23/09/2014, ANEXO 2

d.FR - L'épidémie d'Ebola dans une phase de croissance «explosive»

La Presse, Marie-Noëlle Blessig/AFP Ginebra, 23/09/2014, ANEXO 3

e. FR - Le taux de mortalité du virus Ebola en Afrique de l'Ouest réévalué à $70 \%$

Cuadro 4. Reformulación de la información del ejemplo 4 en su paso de lo especializado a lo divulgativo

\begin{tabular}{|c|c|c|c|c|c|}
\hline EN & $\begin{array}{c}\text { The New England } \\
\text { Journal of } \\
\text { Medicine }\end{array}$ & $\begin{array}{l}\text { Ebola virus } \\
\text { disease }\end{array}$ & in West Africa & $\begin{array}{l}\text { the first } 9 \text { months of } \\
\text { the epidemic }\end{array}$ & forward projections \\
\hline \multirow[t]{3}{*}{ ES } & $A B C$ & infectados & - & - & $\begin{array}{l}\text { prevé } 1,4 \text { millones [...] en } \\
\text { enero }\end{array}$ \\
\hline & El Mundo & casos de ébola & - & - & $\begin{array}{c}\text { teme } 1,4 \text { millones }[\ldots] \text { antes } \\
\text { de enero de } 2015\end{array}$ \\
\hline & El País & $\begin{array}{l}\text { el brote de } \\
\text { ébola }\end{array}$ & - & - & $\begin{array}{c}\text { teme }[\ldots] \text { que supere los } \\
20.000 \text { casos en noviembre }\end{array}$ \\
\hline \multirow{3}{*}{ FR } & La Presse & $\begin{array}{l}\text { L'épidémie } \\
\text { d'Ebola }\end{array}$ & - & - & $\begin{array}{c}\text { dans une phase de } \\
\text { croissance «explosive» }\end{array}$ \\
\hline & Le Figaro & virus Ebola & $\begin{array}{l}\text { en Afrique de } \\
1 \text { 'Ouest }\end{array}$ & - & réévalué à 70\% \\
\hline & Le Monde & Ebola & - & - & $\begin{array}{c}\text { prévoit jusqu'à } 20000 \text { cas } \\
\text { d'ici à novembre }\end{array}$ \\
\hline
\end{tabular}


Le Figaro, Jean-Luc Nothias, 24/09/2014, ANEXO 3

f. FR - Ebola: l'OMS prévoit jusqu'à 20000 cas d'ici à novembre

Le Monde, Paul Benkimoun, 23/09/2014, ANEXO 3

En el cuadro 4 observamos que todos los titulares resaltan los resultados del estudio. A excepción de Le Figaro que recoge tres de los cuatro elementos informativos presentes en el título científico, los demás titulares solo mantienen dos elementos. Podemos ver que El Mundo, El País, Le Monde y La Presse coinciden en la información seleccionada y mantenida en las traducciones, pero cada titular la expresa de una manera determinada. Para «Ebola virus disease» podemos ver que $A B C$ y El Mundo optan por una variación mientras que El País, La Presse, Le Figaro y Le Monde usan la reducción-compresión y proponen varias opciones. «In West Africa» solo se recoge en el titular de Le Figaro, apareciendo traducida tal cual. En los demás titulares se ha decidido su reducciónelisión. «The first 9 months» no se recoge en ninguno de los titulares, así que estamos ante una reducción-elisión. Para «forward projections» se utiliza la variación para reformular estas proyecciones de diferentes maneras, coincidiendo las de $A B C$ y El Mundo (1,4 millones en enero), por un lado, y las del El País y Le Monde (20.000 en noviembre), por otro. En los titulares francófonos encontramos titulares totalmente distintos entre sí en los que se recogen, también, los resultados obtenidos en el estudio.

En este ejemplo no hay traducción literal, sino titulares en los que se recogen las previsiones de la epidemia. En $A B C$ y El Mundo se recogen las previsiones del CDC (Centros de Control y Prevención de enfermedades de EE.UU. $)^{5}$ y en el

5 En las noticias científicas es común recurrir a otras fuentes o a especialistas en la materia para proporcionar información adicional a la del artículo científico. resto de titulares se recogen los resultados del estudio publicado en The New England Journal of Medicine. Las similitudes que se observan entre los titulares de $A B C$ y $E l$ Mundo podrían explicarse por la fuente utilizada en el artículo de El Mundo, efe y Reuters, dado que la noticia se publica el mismo día que el artículo científico. Al publicarse el artículo de $A B C$ un día después, puede que se haya basado en el artículo de estas agencias y de ahí las similitudes. En cuanto a los titulares de El País y Le Monde; la semejanza podría explicarse por los acuerdos establecidos entre estos medios, lo que hace que compartan información ( $c f$. Hernández Guerrero 2005: 156).

\subsection{Resultados}

En el ejemplo 1 se selecciona la misma información proveniente del título científico, el elemento explicado es el mismo y, en todos los titulares, se reformula dicho elemento relacionándolo con el ébola. No son traducciones literales. Las traducciones presentan similitudes entre ellas, sobre todo, en un mismo idioma. Este ejemplo vislumbra una cierta homogeneidad en la traducción del título científico. Es decir, se transmite la misma información utilizando palabras diferentes.

En el ejemplo 2 observamos que el título científico tampoco se traduce literalmente. Los titulares españoles recogen gran parte de la información presente en el título científico altamente especializado. Vemos cómo periódicos con ideología distinta recogen los mismos elementos y proporcionan traducciones parecidas ( $A B C$ y $E l$ País). Los titulares francófonos reformulan «reversion» usando la misma palabra, «espoir», en los tres títulos. En este ejemplo también vemos una cierta homogeneidad en los títulos de un mismo idioma.

En el ejemplo 3, los titulares tampoco se traducen literalmente. Las traducciones españolas 
296 reproducen gran parte de la información recogida en el título científico. La información que se mantiene es la misma, pero se reformula con palabras diferentes. Los títulos francófonos, por su parte, son muy similares entre sí. El título de Le Figaro es una versión recortada de las versiones de La Presse y Le Monde, ambas idénticas. Se observa, asimismo, unos comienzos parecidos en todos los títulos.

En el ejemplo 4 los titulares no se traducen literalmente. En los títulos españoles vemos unas coincidencias parciales, como el uso del mismo verbo en El País y en El Mundo: «teme» o el uso de resultados revelados por el CDC de EE.UU. en $A B C$ y El Mundo. En los títulos francófonos, en cambio, se ven titulares diferentes. A pesar de esta disparidad todos los títulos coinciden en recoger las conclusiones del estudio, pero cada uno lo hace de una manera determinada.

En suma, este análisis nos muestra que la traducción-divulgación de los títulos científicos altamente especializados en la prensa implica:

- no traducción literal;

- selección informativa y su reformulación y recontextualización en una nueva situación comunicativa usando tres técnicas: expansión $=$ amplificación para introducir contenido nuevo, reducción=compresión-elisión para eliminar información o condensar contenido y variación para efectuar cambios en el texto reformulado;

- los títulos de un mismo idioma tienden a presentar similitudes entre ellos $y$, a veces, son idénticos;

- cuando los títulos proceden de Nature o Science $^{6}$, se observa una tendencia homogeneizadora, es decir, coincidencias en la información reformulada.

6 Hablamos de Nature y Science incluyendo sus publicaciones satélites, es decir, Nature Medicine, Nature Cell Biology, Science Translational Medicine, etc.
La elección de los textos a divulgar no fue aleatoria. Estábamos en pleno brote de ébola, se repatriaron casos de personas infectadas a EE.UU. y España ${ }^{7}$ y la OMS autorizó el uso de tratamientos experimentales. Hacía falta divulgar algunos descubrimientos para que las sociedades estén informadas de los últimos descubrimientos. Los diarios deciden utilizar divulgaciones procedentes de comunicados de prensa que envían las revistas, ya que lo reciben prácticamente todo elaborado (Elías, 2008: 88).

\section{DISCUSIÓN}

La ausencia de trabajos sobre la traducción de títulos científicos altamente especializados en la prensa nos ha llevado a realizar esta investigación. Los estudios anteriores se ciñen a la traducción de titulares periodísticos o a la traducción de títulos científicos altamente especializados en el mismo ámbito, es decir, en el especializado. En ellos se ha mostrado que los primeros se adaptan a una nueva situación comunicativa y las convenciones textuales de titulación en la lengua meta y no se traducen literalmente cuando se trata de títulos informativos (Hernández Guerrero, 2004). Los segundos, no se traducen o se traducen cumpliendo con los criterios de precisión y corrección en la lengua de llegada (Soler, 2015).

Aunque somos conscientes de las limitaciones del corpus, nuestros resultados revelan que los títulos científicos altamente especializados no se traducen literalmente en la prensa, sino que se divulgan mediante la aplicación de diferentes técnicas para adaptarlos al nuevo lector. Los titulares se adaptan a la tradición de titulación de la lengua meta, tal como se puede apreciar en los

Dos cooperantes estadounidenses infectados en Liberia y Miguel Pajares repatriado desde Liberia el 7 de agosto de 2014 y fallecido unos días después (12/08/2014). 
titulares españoles que son más informativos. Como se ha podido ver en los ejemplos 1,2 y 3 , la información se selecciona y se reescribe haciendo uso de terminología diferente. Observamos, asimismo, que los títulos que comparten el mismo idioma, a pesar de publicarse en medios con ideologías distintas, en la mayoría de los casos manifiestan reformulaciones similares o incluso títulos idénticos. Así que la orientación del medio no parece influir en este tipo de traducción. El estudio apunta a una tendencia homogeneizadora en la traducción de los títulos científicos provenientes de artículos publicados en Nature y Science.

Partimos del hecho de que los títulos se adaptan a una nueva situación comunicativa y las convenciones textuales de titulación en la lengua meta y nos planteamos como hipótesis que un mismo título traducido en medios de lengua y cultura diferentes se traduciría de diferente manera. Los resultados confirman parcialmente dicha hipótesis. Se corrobora que los títulos se adaptan a las convenciones textuales de la lengua y cultura de llegada, se divulgan para un lector lego y se contextualizan en una nueva situación comunicativa. Pero, se refuta el hecho de que los artículos publicados en medios con ideología diferente se traducen de distinta manera, dado que los resultados revelan que, aunque los títulos se publiquen en medios de diferente ideología, son homogéneos cuando estos provienen de artículos publicados en Nature y Science.

La homogeneidad en las traducciones cuando el título científico proviene de Nature y Science nos lleva a reflexionar sobre si dicha homogeneidad la imponen las revistas especializadas. Según indica Elías (2008: 85-88), algunas revistas científicas, como Nature y Science, han creado gabinetes de prensa con periodistas especializados que transforman un artículo científico en lenguaje de prensa. Estas revistas envían «información precocinada» en un comunicado de prensa a periodistas del mundo entero. En el caso de Nature lo manda con una semana de antelación bajo embargo, lo que permite al periodista documentarse y preparar su artículo con antelación. La política de comunicación de los gabinetes de prensa de estas revistas hace que sean las más usadas por los medios.

Así pues, la política de comunicación de estas revistas podría explicar la tendencia homogeneizadora observada en la reformulación del contenido científico. Es posible que sus gabinetes de prensa actúen como las grandes agencias de información, es decir, emitiendo noticias globales que cada periódico transforma en una noticia local adaptada a las convenciones lingüísticas y culturales de cada uno. El resultado son noticias 'glocales' entendidas según el concepto de 'glocalización’ introducido por Robertson (1994: 38) quien postula que «the concept of globalisation has involved the simultaneity and the inter-penetration of what are conventionnaly called the global and the local».

Cabe señalar que la nota de prensa emitida en inglés por los gabinetes de prensa de estas revistas podría explicar la homogeneidad en la reformulación del contenido científico, pero no explica la reproducción de títulos idénticos en medios diferentes y países diferentes ( $c f$. ejemplo 3). Por tanto, es preciso reflexionar sobre la existencia de otras fuentes. En algunos de los títulos de los ejemplos 1 y 3 , se cita a AFP como fuente. Es un atisbo de que podríamos estar ante múltiples fuentes.

\section{CONCLUSIONES}

A partir de un corpus de títulos científicos publicados en revistas especializadas en inglés y sus traducciones al españoly al francés aparecidas en 
298 algunos periódicos españoles y francófonos, hemos podido observar que, al igual que la traducción de titulares informativos, los títulos científicos altamente especializadas traducidos como noticias científicas en la prensa no se traducen literalmente. Se contextualizan en una nueva situación comunicativa en la que, por un lado, la información científica se adapta a un nuevo destinatario $y$, por otro, se traduce del inglés adaptando el título origen a las convenciones lingüísticas y culturales del lector meta, haciendo que no parezcan traducciones. También se observa una tendencia homogeneizadora en la titulación de un mismo suceso científico en diarios con ideología distinta. Son traducciones 'locales' porque se adecuan a las convenciones textuales de la cultura meta y al mismo tiempo 'globales' porque transmiten ecos similares en periódicos cuyas líneas editoriales son diferentes.

La doble mediación que se hace en la traslación del inglés, lengua de la ciencia, a los demás idiomas y la divulgación de lo altamente especializado a lo divulgativo nos invita a pensar en toda la manipulación que puede incluirse en ese proceso. La traducción implica una acción seleccionadora o gatekeeping (cf. Valdeón, 2016). En el caso de las noticias científicas la primera selección la hacen los gabinetes de prensa de las revistas especializadas, ya que la mayoría de ellas tienen gabinetes de prensa con periodistas especializados. Estos redactan en formato de prensa los contenidos principales de las publicaciones, seleccionan los artículos que formarán parte de los comunicados de prensa y mandan una nota de prensa bajo embargo a los medios del mundo entero con una semana de antelación (Elías, 2008: 88, 96). Según un estudio de De Semir et al. (1998: 295), existe una relación entre la selección de los artículos y su publicación en la prensa. De ahí la tendencia de las revistas de referencia a favorecer los trabajos que se adaptan a las demandas de los medios (Ribas, 1998). Es decir, los responsables de las revistas especializadas y sus gabinetes de prensa favorecen los artículos 'noticiables'. Así pues, los que elaboran los comunicados de prensa de las revistas son «los responsables de la agenda periodística [..], después, los periodistas en los medios que los utilizan» (ibid., 1998). Un estudio de Phillips et al. (1991) revela que los artículos publicados en los medios de comunicación aumentan su índice de citación. En resumen, seleccionar el evento que será noticia, favorecer la publicación de los artículos noticiables por parte de las revistas científicas y seleccionar los artículos que formarán parte de los comunicados de prensa sabiendo que esto aumentará su índice de citación son un indicio de la manipulación que todo ello supone. La segunda selección de información la hacen los periodistas y las agencias de información, ya que son ellos los que «décident et déterminent consciemment quel événement doit être couvert, de quelle manière, avec quelle importance, à quel endroit et selon quelle approche» (Vicente et al., 2010: 10). En este contexto los periódicos manipulan y están manipulados. Seleccionan información y eliminan otra, pero al recibir «noticias precocinadas» $^{8}$ de las revistas especializadas reproducen noticias hechas a la guisa de dichas revistas. En cierto modo esto podría acapararse a lo que Lozano Ascencio et al. (2010: 6) denominan discursos hegemónicos. Los medios se apoyan a menudo en los comunicados de prensa de las revistas especializadas y solo pueden utilizar los artículos seleccionados en ellos (Ribas, 1998). Así pues, si los medios ayudan al lector a hacerse una imagen de los hechos (Montero Küpper y Luna Alonso, 2018; Montero Küpper, 2019), esta es manipulada y distorsionada.

\footnotetext{
8 Véase Elías (2008).
} 
Para concluir, nuestros resultados muestran que los títulos científicos altamente especializados traducidos en la prensa son reescrituras 'glocales' con todo lo que eso implica: «all rewritings, whatever their intention, reflect a certain ideology and a poetics and as such manipulate literature to function in a given society in a given way» (Bassnett y Lefevere, 1993: vii).

Conviene tener en cuenta la manipulación que implica el proceso de traducción-divulgación y reflexionar sobre su naturaleza, sabiendo que se usan múltiples fuentes para reescribir un texto nuevo. Los resultados obtenidos no son concluyentes, ya que no hemos obtenido una cifra de títulos que permite realizar un estudio exhaustivo. No obstante, son útiles para entender cómo se traducen los títulos especializados y puede servirnos de inicio para futuras investigaciones.

\section{REFERENCIAS}

Al DUweIri, Hussein, Baya essayahi, Moulay-Lahssan (2016): «Las técnicas de traducción periodística y su uso en las noticias expositivas», Opción, 32( 7), 17-38.

Ammon, Ulrich (2013): «World languages: Trends and Futures», en Nikolas Coupland (ed.), The Handbook of Language and Globalization, Chichester: Wiley-Blackwell, 101-122.

Andúfar Moreno, Gemma (2006): «La traduction français-espagnol des titres journalistiques du Monde diplomatique, un exemple de tension entre adéquation et acceptabilité», Translational Journal, 10 (3), <https://translationjournal.net/ journal/37titres.htm $>$.

Anónimo (2014): Libro de estilo de El País, Madrid: Aguilar.

Aștirbei, Carmen-Ecaterina (2011): «Particularités de la traduction du texte de presse: le problème du titre journalistique», Traduire, 225,33-48.

BAICchI, Annalisa (2003): «Relational complexity of titles and texts. A semiotic taxonomy», en Lavinia
Merlini Barbaresi (ed.), Complexity in Language and Text, Pisa: Edizione Plus-Universidad de Pisa, 319341.

BASSNETT, Susan y André Lefevere (1993): «General editors' preface», en Palma Zlateva (ed.), Translation as Social Action, Londres: Routledge, vii-viii.

Bielsa, Esperança (2016): «La traducción en los medios de comunicación: una perspectiva cosmopolita», en María Rosario Martín Ruano y África Vidal Claramonte (ed.), Traducción, medios de comunicación, opinión pública, Granada: Comares, 17-34.

Calsamiglia, Helena (1997): «Divulgar: itinerarios discursivos del saber», Quark, 7, <http://quark.prbb. org/7/estrella.htm>.

CHARTIER, Delphine (2000): La traduction journalistique anglais-français, Toulouse: Presses universitaire du Mirail.

CiApuscio, Guiomar Elena (1997): «Lingüística y divulgación de ciencia», Quark, 7, 19-28.

De Semir, Vladimir; Ribas, Cristina y Gemma Revuelta (1998): «Press Releases of Science Journal Articles and Subsequent Newspaper Stories on the Same Topic», JAMA, 280/3, 294-295.

Durand, Charles Xavier (2010): Une colonie ordinaire $d u$ XXIe siècle, Bruselas: E.M.E.

ELías, Carlos (2008): Fundamentos de periodismo científico y divulgación mediática, Madrid: Alianza.

GAMBIER, Yves (2010): «Media, information et traduction à l'ère de la mondialisation», en Roberto A. Valdeón (ed.), Translating Information, Oviedo: Universidad de Oviedo, 13-30.

GARCÍA-Cerviñón, Alberto Hernando (2017): «La configuración lingüística del discurso en la noticia científica», en Luis Alberto Hernando Cuadrado y Jesús Sánchez Lobato (ed.), La configuración lingüísticodiscursiva en el periodismo científico, Madrid: Iberoamericana Vervuert, 107-135.

García SuÁrez, Pablo (2005): «Noticias de agencia: algunos problemas planteados en la traducción español-árabe» en Carmen Cortés Zaborras y María José Hernández Guerrero (ed.), La traducción periodística, Cuenca: Ediciones de la Universidad de Castilla-La Mancha, 175-197.

Gómez Mompart, Josep Lluís (1982): Los titulares en prensa, Barcelona: Mitre. 
300 Goodman, A. Richard; Thacker, Stephen B. y Paul Z. Siegel (2001): «What's in a Title? A descriptive study of article titles in peer-reviewed medical journals», Science Editor, 24, 75-78.

Guyot, Jacques (2010): «La diversidad lingüística en la era de la mundialización», Historia y Comunicación Social, 15, 47-61.

Hernández Guerrero, María José (2004): «La traducción de los titulares periodísticos», en Javier Suso López y Rodrigo López Carrillo (ed.), Le français face aux défis actuels. Histoire, langue et culture, Granada: Universidad de Granada, 271-281.

Hernández Guerrero, María José (2005): «Prensa y traducción» en Carmen Cortés Zaborras y María José Hernández Guerrero (ed.), La traducción periodística, Cuenca: Ediciones de la Universidad de Castilla-La Mancha, 155-173.

Hernández Guerrero, María José (2006): «Técnicas específicas de la traducción periodística», Quaderns: Revista de traducció, 13, 125-139.

HernándeZ Guerrero, María José (2009): Traducción y periodismo, Berna: Peter Lang.

JACOBI, Daniel (1999): La communication scientifique, Grenoble: Presses Universitaires de Grenoble.

Lozano Ascencio, Carlos ; Piñuel Raigada, José Luis y Juan Antonio Gaitán Moya (2010): «Las verdades implantadas en los titulares de prensa sobre los temas de comunicación. Análisis de la construcción de discursos hegemónicos a partir de las auto-referencias hacia la comunicación», Razón y Palabra, 15, <http://www.razonypalabra.org.mx/N/N74/ VARIA74/48LozanoV74.pdf $>$.

LUNA ALONSO, Ana (2019): «Cobertura y tratamiento informativo de la persona que traduce en la prensa», en Silvia montero küpper; Montse Vázquez Gestal e Iván Puentes Rivera (eds.), Comunicación, Traducción e Interpretación, MonTI, 5, 95-121.

Martin-Lagardette, Jean-Luc (2000): Le guide de l'écriture journalistique, París: SYROS.

Montero KüPper, Silvia (2019): «El discurso sobre la traducción en la prensa española (2013-2017)», Cadernos de Linguagem e Sociedade, 20, 132-150.

Montero Küpper, Silvia y Ana Luna Alonso (2018): «The Public Image of Book Translators in the Digital Press», en José Miguel Túñez-López et al. (ed.), Communication: Innovation \& Quality, Berlín: Springer Verlag, 313-328.

NoRD, Christiane (1998): «La unidad de traducción en el enfoque funcionalista», Quaderns: Revista de traducció, 1, 65-77.

Orengo, Albero (2005): «Loalising News: Translation and the 'Global-national' Dicotomy», Language and Intercultural Communication, 5/2, 168-187.

PHilliPs, David P.; Kanter, Elliot J.; Bednarczyk, Bridget y Patricia L. Tastad (1991): «Importance of the Lay Press in the Transmission of Medical Knowledge to the Scientific Community», The New England Journal of Medicine, 325/16, 1180-1183.

Reque de Coulon, Ana (2002): «Análisis de estrategias y procedimientos de traducción utilizados en los títulos de la versión española de Le Monde diplomatique», Hermēneus, 4, 147-159.

Ribas, Cristina (1998): «La influencia de los press releases, según el color del cristal con que se mire», Quark, 10, 32-37.

ROBERTSON, Roland (1994): «Globalisation or glocalisation?», Journal of Internationa Communication, 1/1, 33-52.

Roqueplo, Philippe (1983): El reparto del saber, trad. Rubén Núñez, Buenos Aires: Gedisa.

SolER, Viviana (2007): «Writing titles in science: An exploratory study», English for Specific Purposes, 26, 90-102.

Soler, Viviana (2011): «Comparative and contrastive observations on scientific titles written in English and Spanish», English for Specific Purposes, 30, 124137.

Soler, Viviana (2015): «Traducción de títulos científicos altamente especializados: hacia un estado de la cuestión», Trabalhos em Lingüística Aplicada, 54, 9-28.

TOURY, Gideon (2004): Los estudios descriptivos de traducción y más allá. Metodología de la investigación en estudios de traducción, trad. Rosa Rabadán y Raquel Merino, Madrid: Cátedra.

VALDEÓN, Roberto (2016): «Traducción periodística y gatekeeping», en María Rosario Martín Ruano y África Vidal Claramonte (ed.), Traducción, medios de comunicación, opinión pública, Granada: Comares, 35-51. 
van DIJK, Teun Adrianus (1990): La noticia como discurso, Barcelona: Paidós.

Vella Ramírez, Mercedes y Ana Belén Martínez López (2012): «Análisis de estrategias y procedimientos traductológicos utilizados por El País en la traducción de títulos de prensa del español al inglés», Sendebar, 23, 177-206.

Vicente, Miguel; Otero, Miguel; López, Pablo y Miguel Pardo (2010): L'image du monde Arabo-Musulman dans la presse espagnole, Fondation des Trois Cultures de la Méditerranée et Centre de recherche en communication et analyse des médias, $<$ http://tresculturas.org/tresculturas/wp-content/ uploads/2010/05/Informe-cicam-frances-1.pdf $>$.

\section{ANEXOS}

Referencias de los artículos científicos y divulgativos que constituyen nuestro corpus:

\section{Anexo 1: Corpus en inglés}

Aylward, Bruce; Barboza, Philippe et al. (2014): «Ebola Virus Disease in West Africa - The first 9 Months of the Epidemic and Forward Projections», The New England Journal of Medicine, 371/16, 1481-1495.

QUI, Xiangguo; Wong, Gary et al. (2014): «Reversion of advanced Ebola virus disease in nonhuman primates with Zmapp», Nature, 514/7520, 47-53.

Stanley, Daphne A.; Honko, Anna N. et al. (2014): «Chimpanzee adenovirus vaccine generates acute and durable protective immunity against ebolavirus challenge», Nature Medicine, 20/10, 1126-1129.

THI, Emily P., Mire; Chad E. et al. (2014): «Marburg virus infection in nonhuman primates: Therapeutic treatment by lipid-encapsulated siRNA», Science Translational Medicine, 6/250, 116-140.

Anexo 2: Corpus en español

Agencias (2014): «La OMS teme que el brote de ébola supere los 20.000 casos en noviembre», El País, 23 de septiembre, <https://elpais.com/sociedad/2014/09/23/actualidad/1411455384_646890. html>.
Agencias (2014): «Una vacuna experimental contra el ébola protege a monos durante diez meses», $A B C$, 9 de septiembre, <http://www.abc.es/sociedad/20140908/rc-vacuna-experimental-contraebola-201409080349.html>.

Domínguez, Nuño (2014): «El fármaco experimental cura el ébola en monos», El País, 29 de agosto, <https://elpais.com/elpais/2014/10/07/ciencia/1412678414_835681.html>.

Efe (2014): «El fármaco contra el ébola ZMapp demuestra su efectividad en primates», $A B C$, 29 de agosto, <http://www.abc.es/sociedad/20140829/abci-farmaco-ebola-efectivo-primates-201408292005.html>.

EfE (2014): «Una vacuna contra el ébola logra inmunizar a primates durante 10 meses», $A B C$, 8 de septiembre, <http://www.abc.es/sociedad/20140907/ abci-vacuna-contra-ebola-logra-201409071941. html>.

EFE y Reuters (2014): «EE.UU. teme 1,4 millones de casos de ébola antes de enero de 2015», El Mundo, 23 de septiembre, <http://www.elmundo.es/salud/20 14/09/23/5420f4f622601d7a538b456c.html>.

G. Lucio, Cristina (2014): «Un espaldarazo para ZMapp», El Mundo, 29 de agosto, <http://www. elmundo.es/salud/2014/08/29/5400b78c22601do 2178b4585.html>.

G. Lucio, Cristina (2014): «Una esperanza para el 'primo' más cercano del ébola», El Mundo, 21 de agosto, <http://www.elmundo.es/salud/2014/08/21/53 f4cd52e2704e64228b4586.html>.

López Sánchez, Gonzalo (2014): «Diseñan una posible cura para el «hermano» del ébola, el virus Marburgo», $A B C, 20$ de agosto, <http://www.abc. es/sociedad/20140820/abci-cura-virus-marburgo-201408201707.html>.

López, Ángeles (2014): «La primera vacuna frente al ébola muestra su protección en animales», $E l$ Mundo, 7 de septiembre, <http://www.elmundo.es/salud/2014/09/07/5409b603ca47418208 8b4583.html>.

Molano, Eduardo S. (2014): «En el peor escenario, EE.UU. prevé 1,4 millones de infectados en enero», $A B C, 24$ de septiembre, <http://hemeroteca. 
302 abc.es/nav/Navigate.exe/hemeroteca/madrid/ abc/2014/09/24/044.html>.

\section{Anexo 3 : Corpus en francés}

AFP (2014): «Ebola: un vaccin expérimental validé par les essais sur des singes», La Presse, 7 de septiembre, <https://www.lapresse.ca/international/ dossiers/virus-ebola/201409/07/01-4797934-ebola-un-vaccin-experimental-valide-par-les-essaissur-des-singes.php>.

Benkimoun, Paul (2014): «L'OMS prévoit jusqu'à 20 000 cas d'ici à novembre», Le Monde, 23 de septiembre, <http://www.lemonde.fr/planete/article/2014/09/23/ebola-1-oms-prevoit-jusqu-a20-000-cas-d-ici-a-novembre_4492686_3244. html>.

Blessig, Marie-Noëlle (2014): «L'épidémie d’Ebola dans une phase de croissance explosive», La Presse, 23 de septiembre, <https://www.lapresse.ca/ international/dossiers/virus-ebola/201409/23/014802741 - lepidemie - debola-dans - une phase-de-croissance-explosive.php $>$.

Cabut, Sandrine (2014): «L'espoir d'un traitement contre Ebola conforté par de nouvelles études», Le Monde, 30 de agosto, <http://www.lemonde. $\mathrm{fr} /$ planete/article/2014/08/30/1-espoir-d-un-traitement-contre-ebola-conforte-par-de-nouvellesetudes_4479290_3244.html>.

Herchoovitch, Jonathan (2014): «Un traitement pour le virus Marburg, cousin d'Ebola», Le Figaro, 21 de agosto, <http://sante.lefigaro.fr/ actualite/2014/08/21/22712-traitement-pour-virus-marburg-cousin-debola $>$.

LE Figaro y AFP (2014): «Ebola: un vaccin validé chez les singes», Le Figaro, 7 de septiembre, <http:// www.lefigaro.fr/flash-actu/2014/09/07/9700120140907FILWWW00175-ebola-un-vaccin-valide-chez-les-singes.php>.

Le Monde y AFP (2014): «Ebola: un vaccin expérimental validé par les essais sur des singes», Le Monde, 7 de septiembre, <http://www.lemonde. fr/planete/article/2014/09/07/ebola-un-vaccinexperimental-valide-par-les-essais-sur-des-singes_4483346_3244.html>.
Le Monde y AFP (2014): «Vers un traitement contre le virus de Marburg, très proche de celui d'Ebola», Le Monde, 21 de agosto, <http://www.lemonde.fr/ sciences/article/2014/08/21/vers-un-traitementcontre-le-virus-de-marburg-tres-proche-de-celui-d-ebola_4474118_1650684.html>.

Nothias, Jean-Luc (2014): «Le taux de mortalité du virus Ebola en Afrique de l'Ouest réévalué à $70 \% »$, Le Figaro, 24 de septiembre, <http://sante.lefigaro. fr/actualite/2014/09/24/22819-taux-mortalitevirus-ebola-afrique-louest-reevalue-70 $>$.

Perrault, Laura-Julie (2014): «Virus Ebola: lueur d'espoir canadienne au bout d'un tunnel qui s'obscurcit», La Presse, 30 de agosto, <https:// www.lapresse.ca/international/dossiers/virusebola/201408/30/01-4795880-virus-ebola-lueurdespoir-canadienne-au-bout-dun-tunnel-quisobscurcit.php>.

VANLerberghe, Cyrille (2014): «L'espoir des premiers traitements expérimentaux», Le Figaro, 29 de agosto, <http://sante.lefigaro.fr/ actualite/2014/08/29/22732-lespoir-premierstraitements-experimentaux $>$. 